\title{
Grateful Med: Direct Access to MEDLINE for Health Professionals with Personal Computers
}

\author{
Josephine L. DORSCH M.A.L.S. ${ }^{\text {a }}$, John G. FAUGHNAN M.D. ${ }^{\text {b }}$, \\ and Betsy L. HUMPHREYS M.L.S. ${ }^{\mathrm{c}}$ \\ a Professor Emerita, University of Illinois - Chicago \\ $b$ Veterans Health Administration \\ c U.S. National Library of Medicine (Retired)
}

\begin{abstract}
Donald A.B. Lindberg M.D. arrived as Director, U.S. National Library of Medicine (NLM) in late 1984 with the intention of implementing a physicianfriendly interface to MEDLINE, a prime example of his interest in making NLM information services more directly useful in medical care. By early 1986, NLM's Grateful Med, an inexpensive PC search interface to MEDLINE useful for health professionals, had joined the group of end-user systems for searching MEDLINE that emerged in the 1980s. This chapter recounts Grateful Med's rapid iterative development and the subsequent campaign to bring it to attention of health professionals. It emphasizes Lindberg's role, the challenges faced by those introducing and using the interface in a pre-Internet world, and some longer-term effects of the effort to expand health professionals' use of MEDLINE during the decade from 1986 to 1996.
\end{abstract}

Keywords. Donald A.B. Lindberg M.D., U.S. National Library of Medicine, MEDLARS, Grateful Med, User-Computer Interface

\section{Introduction}

When Donald A.B. Lindberg M.D. was sworn in as Director in October 1984, the U.S. National Library of Medicine (NLM) served health professionals primarily through libraries in hospitals and academic institutions. In general, specially trained librarians used command language interfaces to search MEDLINE, NLM's online index to articles in biomedical journals, and other databases on behalf of "end users", including physicians and scientists. They used commercial telecommunications network connections to reach systems at NLM and commercial database providers. Libraries delivered hard copies of full text articles identified in the searches from local collections or via interlibrary loan through an NLM-directed library network, then called the Regional Medical Library (RML) Network [1].

The number of health professionals searching NLM databases directly was small, but it was increasing. In 1984, NLM and its Network training centers introduced new six-hour "Basics of Searching MEDLINE" classes targeted to health professionals and

\footnotetext{
${ }^{1}$ Corresponding Author, Betsy L. Humphreys, $362510^{\text {th }}$ St. North, Unit 305, Arlington, VA 22201, USA; betsyhumphreys@verizion.net
} 
new "Train the Trainers" courses to prepare more librarians to teach these classes to health professionals. By 1985, librarians in many medical schools had begun to teach command language searching to faculty and students and were enjoying an increase in status as a result [2]. In some cases, they provided "user-friendly" interfaces to locally mounted subsets of MEDLINE data for direct use by faculty, staff, and students, thereby reducing telecommunications costs as well as improving access. NLM grants had supported development of some systems for end user searching of MEDLINE subsets, including Paper Chase [3] and MiniMEDLINE [4].

Lindberg arrived at NLM with the intention of implementing a physician-friendly interface to MEDLINE and other MEDLARS databases, a prime example of his interest in making NLM information services more directly useful in medical care. Lindberg viewed the then-rapid uptake of IBM Personal Computers (PCs) as an opportunity to make MEDLINE available nearer the point of clinical decision making, including to physicians not well connected to medical libraries. Professional associations, including the American Medical Association, and commercial database providers had also recently begun marketing online medical information services to individual physicians with PCs.

This chapter describes NLM's rapid development of an inexpensive PC search interface useful for health professionals and the subsequent campaign to bring it to the attention of the target audience. The focus is on Lindberg's role, the challenges faced by those introducing and using the interface in a pre-Internet world, and some longer-term effects of the effort to expand health professionals' use of MEDLINE during the decade from 1986 to 1996.

\section{Defining the Goal and Developing the Product}

In theory, NLM had at least three options for providing a user-friendly interface to MEDLINE for health professionals with PCs: (1) modification of the ELHILL command language search system resident on NLM's mainframe computer; (2) a front-end search program to interface with the existing ELHILL system; or (3) a MEDLINE CD-ROM product using the format just announced by Philips and Sony in 1984.

Lindberg quickly dismissed the first and third options. Modifying ELHILL's "spaghetti code" would be too time-consuming and unlikely to succeed, as an earlier failed NLM attempt to add a user-friendly option had demonstrated. With typical prescience, Lindberg saw CD-ROMs as a dead-end technology with drawbacks for users, e.g., always out-of-date, requiring local database management, and for NLM, e.g., no direct connection to and feedback from - or ability to count - users. This reasoning also explains his lack of enthusiasm for institutional access to MEDLINE subsets. Lindberg did acknowledge that institutional subsets and MEDLINE CD-ROMs were useful in some circumstances. He encouraged commercial development of CD-ROM products by providing free access to MEDLINE data and technical advice during the development phase and arranging for libraries to assist in product evaluation [5]. Meanwhile, he focused NLM on a front-end software interface to NLM's mainframe search system.

Lindberg defined the goal as a search mechanism that didn't require experience with logging on, the ELHILL command language, or NLM's controlled vocabulary, the Medical Subject Headings (MeSH). It should be easy to use, inexpensive, support growing search sophistication, require minimal documentation, and have extensive online help. In accordance with his strongly preferred approach for any system 
development project, the plan was for evolutionary development of successive "smarter" versions of the software, each reflecting user feedback on the previous one [6].

Two months after Lindberg was sworn in as NLM Director, Rose Marie Woodsmall attended a meeting with John Anderson, Director of Information Systems, and Lois Ann Colaianni, Associate Director for Library Operations, among others, and learned that "Dr. L. wants a concrete proposal for end user services" [6,p.164]. She was well qualified for the NLM development team, having worked on the AIM-TWX experiment that first married online searching with commercial telecommunications networks, the release of MEDLINE in 1971, and subsequently on MEDLARS enhancements, training, and user services. Her first assignment was to survey existing operational or prototype end-user search systems and to prepare a report on the state-of-the-art with recommendations for possible NLM next steps, including any existing commercial systems that NLM might endorse or purchase [6].

Woodsmall completed the comparison of twenty-four operational and prototype systems in early February 1985. The MICROSEARCH prototype selected by NLM was the last system to be added to the comparison project. Woodsmall learned about it by chance at dinner with Grace and Davis McCarn, friends and distinguished former NLM colleagues [7]. While at NLM, Davis McCarn had directed the development of NLM's AIM-TWX experiment, MEDLINE, and the NLM ELHILL search system. Recently he had created the MICROSEARCH prototype. It not only met Lindberg's criteria but was designed to interface with an ELHILL derivative. Query assembly was done on the microcomputer, before the connection to the mainframe was made, to keep search costs low. By mid-February 1985, Lindberg and the NLM development team had decided to work with Online Information International (McCarn's company) to adapt the MICROSEARCH prototype to the NLM environment. This was seen as "a notespecially-overwhelming task given its common NLM/ELHILL origin," a more than slight understatement [6, p.165].

Just a year later, in February 1986, Woodsmall and Larry Thompson, then editor of the Health Section of the Washington Post, gave the first public demonstration of Grateful Med, the NLM front end package for IBM PCs, at a Science Writers Symposium. The symposium was an early event in the yearlong celebration of NLM's $150^{\text {th }}$ anniversary. The name Grateful Med, a nod to the rock band Grateful Dead, was Lindberg's choice ("It's just too good to pass up.") from a list of options presented to him [8]. Initial reactions to the name were mixed: you loved it or hated it, but, as time would tell, neither you nor the media ever forgot it. The name proved to be a tremendous asset to another Lindberg priority: educating the public and the Congress about NLM and its programs and services.

Woodsmall and Siegel have recounted the fast pace of iterative development during the year between selection of the base prototype and the release of public version 1, as well as the subsequent two years of refinements, extensions, and necessary institutional adjustments at NLM [6]. Rapid iteration required a highly interactive team approach between NLM librarians, information systems staff, and the prototype developer. Lindberg, other NLM senior staff, NLM Regents, and selected visitors, including members of the NLM Long Range Planning Panels meeting at the Library in 1985, provided periodic review and valuable feedback. Formal multi-phase Beta testing by both target end users and Network librarians occurred from September 1985 to January 1986. In the early years, Woodsmall coordinated feedback from Grateful Med usertesters or "Rose's groupies" as Lindberg called them. He viewed her interactions with them as a gold standard for user involvement in system development. 


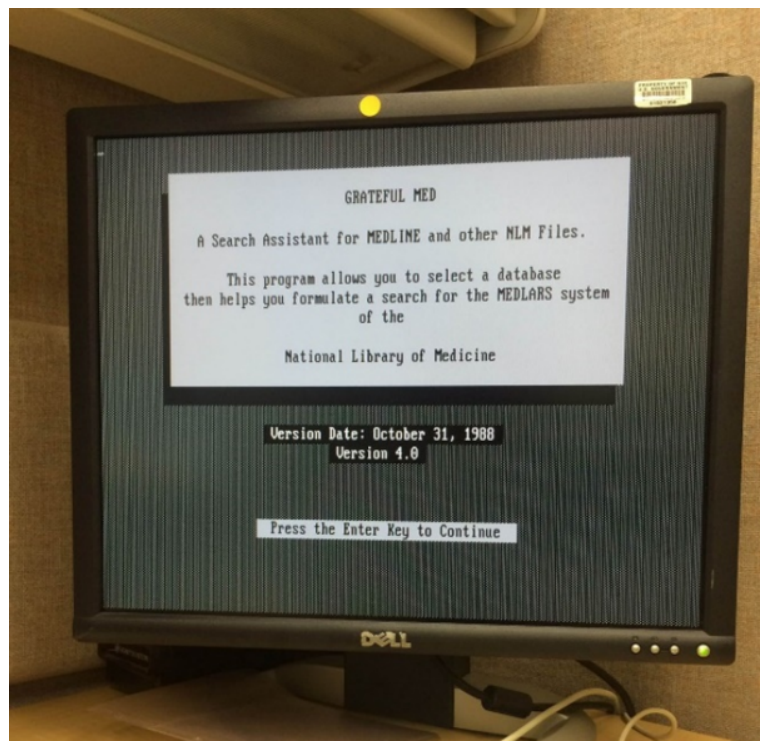

Photo 1: The Grateful Med home screen. Photograph courtesy of Nicole Contaxis.

The methods of interaction evolved, but NLM maintained a feedback loop with users/testers of all new versions of Grateful Med. Eventually there was a suite of locally mounted Grateful Med products: the original PC-DOS, Macintosh, and (short-lived) PCWindows products; a Grateful Med Search Engine which allowed developers to use the code for Grateful Med's connection to ELHILL while providing a different user interface; a single-copy local area network (LAN) version serving multiple users, and the addition of the Internet as one of the telecommunications options [9]. Lindberg signed off on new features in all versions throughout their lifetimes. He initiated the development of the Search Engine version in 1988 to ease connections between external systems and MEDLINE for Unified Medical Language System (UMLS) researchers [e.g., 10]. As the first Director of the National Coordination Office for High Performance Computing and Communications, Lindberg applauded the use of the National Center for Supercomputer Applications' Telnet TCP/IP source code in developing the LAN version. He also directed NLM efforts to greatly expand access to the Internet and Webcapable workstations. This eventually eliminated the need for locally installed versions of Grateful Med in 1996, when Internet Grateful Med debuted.

\section{Pursuing the Target Audience}

Users purchased Grateful Med from the National Technical Information Service (NTIS) for a one-time fee of about twenty-five dollars. Software updates were distributed to users free of charge. Users applied to NLM for a logon code for the NLM system. They were billed by the U.S. National Technical Information Service (NTIS)based on the amount of searching done, primarily to cover their fair share of commercial telecommunications charges. With more than 6,500 copies sold in the first 20 months, Grateful Med was a major reason for the big jump in the number of individuals with logon codes for NLM's system from FY 1985 (630) to FY 1987 (at least 9,000) This 
increase in users was more than sufficient to require major changes in NLM procedures for issuing codes and providing customer service. It was, however, a tiny fraction of the target audience for Grateful Med, which included hundreds of thousands of health professionals who had a PC or might decide that direct access to MEDLINE was a good reason to obtain one.

As then funded and oriented, the RML Network, NLM's established mechanism for serving individual health professionals, could reach a subset of this audience, primarily those connected to a hospital or an academic institution with a health sciences library, although the goal of the Network was broader. Arguably, those with existing library service had a less serious need for Grateful Med, but many early users were in fact students, faculty, and staff who learned about it from the librarians serving their institutions. A greatly expanded NLM publicity program, initiated by Lindberg, supported by the recently formed Friends of the National Library of Medicine (FNLM), abetted by the buzz around the name Grateful Med, and explicitly authorized by Congress in December 1987, attracted early users, too.

Nonetheless, NLM needed new ways to bring its reasonably inexpensive userfriendly search interface to the attention of many more health professionals. A 1989 report by the NLM Outreach Planning Panel of the Regents of the NLM, known as the DeBakey Report after the Panel's chair, Michael E. DeBakey, MD, saw the combination of new end-user services and active outreach as a powerful way for NLM to pursue its goal of enhancing access to medical information by health professionals who currently lacked library services [11]. The report helped Lindberg obtain additional funding for a new outreach initiative relying heavily on health sciences librarians to reach out to rural, underserved, minority, and unaffiliated health professionals. Between 1990-1992 fiftyeight competitive Grateful Med outreach project awards were made to libraries in academic centers, hospitals, other health care institutions, and professional organizations. These projects were part of NLM's broader outreach programs through the Regional Medical Library Network, renamed the National Network of Libraries of Medicine in 1991 as recommended in the DeBakey report.

In other responses to the report, Lindberg encouraged outreach efforts led by health professionals, hired an in-house marketing manager, and approved flat-rate pricing arrangements for individual users affiliated with a participating institution or professional association. One poorly conceived marketing attempt, a letter about Grateful Med to hospital administrators with no mention of hospital librarians, led some to the erroneous conclusion that Lindberg did not value librarians [12]. It took time for some to become comfortable with the notion of NLM marketing services directly to health professionals.

\section{Grateful Med Outreach - Librarian Experience}

The Grateful Med outreach projects were meant to demonstrate or teach underserved health professionals how to use Grateful Med as an easy and convenient way to obtain up-to-date medical information for their practices. Although Grateful Med was a relatively easy-to-use system, there were barriers to its adaptation and use. The projects took place in underserved, and often underfunded, rural and inner-city locations. These targeted health professionals often lacked affiliation with a medical library. The project librarians provided training in the use of Grateful Med to search the NLM databases, but also became a conduit to library information and document delivery services. The 
"Loansome Doc" feature, added to Grateful Med in 1991, made it easy to send electronic requests for articles identified in searches to cooperating libraries. The feature's name, approved by Lindberg, was a take-off on the hugely popular Lonesome Dove television mini-series, based on a book of the same name by Larry McMurtry.

Librarians headed out equipped with twenty-pound "portable" computers, printers, projectors, and hundreds of feet of telephone and extension cords. They provided training to diverse groups including physicians, nurses, dentists, administrators, physical therapists, and other health professionals in the form of demonstrations, formal instruction, and hands-on sessions for small groups or individuals at hospitals, clinics, and public health departments. Exhibits and continuing education sessions at professional meetings provided another way to engage health professionals while they were free of clinical responsibilities.

Training materials developed by NLM were colorful and easy to read. Project librarians could easily tailor them to local needs and training levels from novice to advanced user. On-screen instructions led the user through search strategy construction with Author, Title, Subject, English Only, Review Only, and Journal Abbreviation choices. The search was transmitted to NLM and the search results were sent to the user with the option of including Abstracts. Based on the user's choice of relevant citations, NLM also transmitted suggested MeSH terms helpful for editing a search. This feature gave trainers an opening to discuss searching the database with controlled vocabulary. Loansome Doc could then be used to procure the articles from the Grateful Med project library, often free of charge, or from other cooperating libraries.

The success of Grateful Med outreach efforts was ultimately measured by the number of people who indicated they intended to use Grateful Med when they applied for a logon code for the NLM system. It was often predicated on the "readiness" of both individuals and any institutions concerned. Although Grateful Med was designed as an easy interface to MEDLINE even a novice could navigate with built-in instructions for searching, some health care professionals did not own a personal computer and lacked even basic computing skills.

Lack of computer equipment and inadequate telecommunications systems were major barriers at the underserved hospitals, clinics, and public health departments where many training sessions took place. Rural locations suffered from outdated telephone systems which resulted in difficulty establishing online connections with NLM computers. In many instances the equipment provided by the project was the only computer available for searching Grateful Med at an institution. Medical records personnel or education coordinators often became intermediaries to conduct searches and request documents for others at their institutions because of the lack of computers. Clinicians often cited "lack of time" as a barrier.

A survey of participants in two projects in "Forgottonia," farm-based communities with populations below 30,000 in central Illinois, showed initial field work required follow up and continuation to sustain long-term improvement in information access [13]. The authors concluded that satisfying the information needs of rural health professionals would require multiple approaches over a continuum, and adoption of end-user searching would not be universal. Follow-up projects incorporated lessons learned including such options as advanced sessions, varied training session lengths, award of continuing education credits, extended periods of equipment loan, free document delivery, one-onone intensive training for personnel acting as intermediary searchers, and working with institutions to formalize relationships with an outreach library. Evaluation showed the benefits of readiness, re-exposure, and reinforcement [14]. In follow up visits, the users 
were found to be less computer phobic. There was recognition that computer access was becoming a necessity, and institutions were more likely to have a dedicated Grateful Med computer. Among physicians especially, Grateful Med had gained name recognition and credence through exposure at professional meetings. The follow-up projects also helped to keep health professionals current with the changing Grateful Med software, Loansome Doc, and Internet Grateful Med.

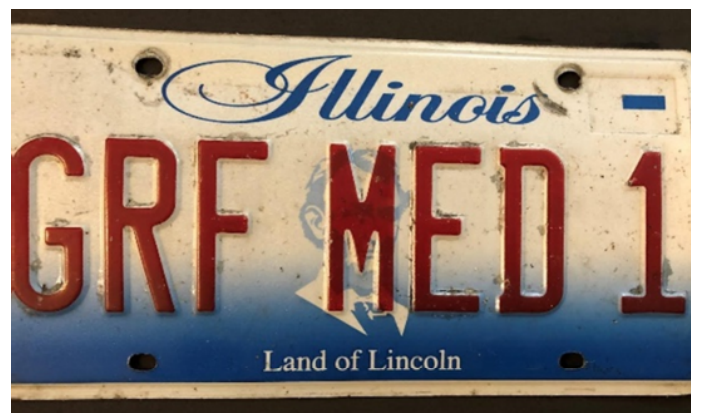

Photo 2: A license plate retired along with Grateful Med after many outreach miles in Illinois and Iowa. Photograph courtesy of Josophine Dorsch.

\section{Grateful Med Use - Clinician Experience}

Medical students of the early 1980s still knew their way around the many shelves of the monthly Index Medicus, but by then librarians relied on terminal based MEDLARS searching. By the mid-80s paper Index Medicus updates became less relevant to everyone; physicians relied on librarians to search the literature and provide photocopies of journal articles. Shelves and filing cabinets were filled with stapled photocopies of journal articles. Some were organized by topics or by Library of Congress categories, but by the mid-1980s personal computer "database" apps were being used to manage these personal analog libraries. Soon Grateful Med would change all this.

The very early versions of Grateful Med ran on "IBM PC" $360 \mathrm{~K}$ floppy disks that somehow managed to include a browsable MeSH hierarchy (Mac versions came later). The software made it easy for novice users to work with the formal search terms and modifiers. Although the floppy disks were slow to work with, the software itself was simple to understand and use.

The Grateful Med software was easy to use, but connectivity was another matter. Home digital connections were unheard of, and even hospitals and medical schools relied on modems to transform digital data into analog sounds for transmission on phone lines. Transmission rates were slow; it was easy to read Grateful Med search results as they slowly scrolled down an 80-character wide green text computer screen.

Slow speeds were not the biggest communications challenge, however. These modems had no error correction! Grateful Med worked well until an errant sound on the phone line was converted into an unexpected character or any one of about 128 nonalphanumeric symbols. Modems also varied greatly in their ability to speak to one another; users might have to apply obscure Hayes commands to tweak their modem's behavior. 
At that time Grateful Med use took patience and persistence, but the prize was worth the price. In an age when years passed between updates of paper textbooks quality medical care relied on the current medical knowledge available in journals. Prior to Grateful Med, researching a clinical question was largely limited to academic health care centers. Grateful Med was changing the landscape of health care everywhere including Michigan's highly rural Upper Peninsula (UP).

Grateful Med came to the UP through Michigan State University School of Medicine and the Upper Peninsula Health Education Corporation. These programs funded a rural medical student track including a year of primary care in the town of Escanaba. This rural/academic setting was a great launchpad for taking Grateful Med to medical students, rural physicians, physician assistants, and nurse practitioners.

With support from the National Library of Medicine's Grateful Med Outreach program, demonstrations were performed at medical society and other meetings across the Upper Peninsula. Early training sessions using rural phone lines were challenging. A July 1991 training session with clinicians at Iron Mountain Michigan's VA Medical Center in July 1991 inspired one clinician to reinvent noise filtering! Soon more reliable modems with noise cancellation arrived and Grateful Med became a pleasure to use and teach. Within another year Grateful Med went beyond providing references and abstracts and added the ability to request articles from medical libraries including from Michigan State University's system. Rural physicians began learning what we now call evidencebased medicine.

1996 brought Internet Grateful Med (no more modems!). Locally mounted versions of Grateful Med were retired, but most Grateful Med veterans know it took several years for online Internet successors to approach the efficiency and simplicity of searching on the original Grateful Med.

\section{The Impact of Grateful Med}

As Lindberg intended, Grateful Med provided direct affordable access to MEDLINE and other NLM databases for many health professionals, as well for students, scientists, health administrators, and journalists. From 1986 to 1996, versions of Grateful Med and the special efforts to promote their use increased the number of individual end users with NLM logon codes from less than 1,000 to more than 100,000. Grateful Med demonstration and training projects increased the levels of awareness and use of MEDLINE and other library services by a diverse group of health professionals, with particular emphasis on the underserved [15]. Lindberg made effective use of maps to show members of Congress how their support of NLM outreach was translating into more people with access to medical information in their states and districts.

Grateful Med was a prominent member of a group of end-user systems for searching MEDLINE that emerged in the 1980s. During the 1980s and early 1990s, direct access to MEDLINE via one or more of these systems and related search training became the norm for students and faculty in U.S. medical schools and many nursing schools. Librarians introduced Grateful Med as an end-user option in the public service settings in academic and hospital libraries, often assuming the cost of searching as part of the library budget. In addition to low cost, Grateful Med had the advantage of availability wherever students and faculty might go to continue their education or careers.

Many health professional users of Grateful Med and other search interfaces relied heavily on the abstracts retrieved from MEDLINE. Although the cost of copies of papers 
was an obvious deterrent, clinicians' lack of time to obtain the complete papers (free electronic full text was in the future) and to read them was often a bigger problem. As more clinicians gained access to abstracts in MEDLINE via Grateful Med, Lindberg encouraged the efforts of R. Brian Haynes, MD, Ph.D. and Edward Huth, MD, Editor, Annals of Internal Medicine to promote more informative, structured abstracts for clinically significant articles [16]. Lindberg directed NLM staff to make changes necessary to accommodate the first structured abstracts in MEDLINE in 1989 and encouraged NLM staff to track their adoption [e.g., 17]. In 2020, 29 per cent of citations added to MEDLINE had structured abstracts [18].

Structured abstracts were an early step in easing the burden of assessing published evidence for busy clinicians. As health professionals' use of Grateful Med and other interfaces to MEDLINE grew, the benefits, but also the limitations, of MEDLINE as an aid to evidence-based decision-making became clearer. In many cases, clinicians looking for answers to clinical questions were best served by an updated synthesis of best clinical evidence. A well-written abstract to a recent review article might meet this need, if there was one, but that was unlikely for many clinical questions. There were few regularly updated sources of synthesized clinical evidence in the 1980s. The U.S. National Cancer Institute's Physician Data Query (PDQ) system was a shining exception [19]. The growth in the number of health professionals using Grateful Med and other MEDLINE interfaces helped to establish the need and the market for additional sources of synthesized clinical evidence, and many emerged in the 1990s.

The Grateful Med outreach projects had a significant impact on NLM's Library Network. These projects were the first exposure for many Network librarians to the joys and challenges of working with potential users outside their home institutions. They provided a useful set of lessons learned for future Network outreach initiatives. For example, early success in reaching health professionals at professional meetings led NLM and the RMLs to establish an extensive schedule of exhibits and demonstrations at such meetings in many subsequent years.

The projects extended the services provided by health sciences libraries and fostered increased collaborative activity among libraries. As predicted, they had continuing effects as libraries expanded training and service activities and as the individuals trained continued to use MEDLINE and other NLM services [14]. The opportunity to contribute to improved rural and inner-city health care through the introduction of computerized information retrieval and a link to a health sciences library was a worthy motivation for participating libraries which resulted in benefits for all involved [12].

Teaching use of Grateful Med and other interfaces to NLM databases in librarians' home institutions increased recognition of librarians' expertise. For some librarians, it became the entry point into the information management and evidence-based medicine (then called critical appraisal) curricula within medical and nursing schools.

As it happened, Grateful Med did not have a lasting impact on NLM user interface design, likely to Lindberg's regret. (The Loansome Doc feature is the one exception; it endured in some form until mid-2019.) In 1997, MEDLINE was the first NLM database migrated from the legacy ELHILL search system to Entrez. The Entrez system was a much more flexible search engine developed by NLM's National Center for Biotechnology Information (NCBI) for linked retrieval of gene sequences, MEDLINE records, and some full text on publisher's websites. Entrez's Web-based MEDLINE search interface, PubMed, had a simple search box, similar to the Internet search engines which had appeared after the advent of Web browsers in 1993. It also had useful precomputed connections among related articles and data. 
When MEDLINE became free via the Internet, both Internet Grateful Med, which had interactive search optimization features using UMLS knowledge, and PubMed were available as interfaces. Use immediately increased 10-fold, with the simpler PubMed interface attracting the majority of new users. The ensuing rapid pace of changes and improvements to MEDLINE searching via Entrez/PubMed made it difficult to maintain the Internet Grateful Med interface to that database. Internet Grateful Med played a crucial role in providing access to other NLM databases during the transition away from ELHILL and was retired in 2001.

In comparison to many NLM services, locally mounted versions of Grateful Med had a short history, ended by the spread of Internet access to health professionals, health care institutions, and libraries which Lindberg and NLM had helped to hasten. In February 1986, however, less than 18 months after he arrived as NLM Director, Grateful Med's initial release sent a powerful message about Donald A.B. Lindberg M.D. He was committed to using technology and publicity to expand access to NLM services, he was leading NLM ahead rapidly, and he had a sense of humor.

\section{References}

[1] Bunting A. The nation's health information network: history of the Regional Medical Library Program. Bull Med Libr Assoc. 1987 Jul;75(3 Suppl):1-62.

[2] Welborn V, Kuehn JJ. End-user programs in medical school libraries: a survey. Bull Med Libr Assoc. 1988 Apr;76(2):137-140.

[3] Horowitz GL, Bleich HL. PaperChase: a computer program to search the medical literature. N Engl J Med. 1981 Oct 15;305(16):924-30.

[4] Broering NC. The Georgetown University Library Information System (LIS): a minicomputer-based integrated library system. Bull Med Libr Assoc. 1983 Jul;71(3):317-23.

[5] Woodsmall RM, Lyon-Hartmann B, Siegel ER editors. MEDLINE on CD-ROM: National Library of Medicine evaluation forum, Bethesda, Maryland, September 23, 1988. Medford, NJ: Learned Information, 1989.

[6] Woodsmall RM, Siegel ER. Reconciling design philosophy and user expectations. In: Siegel MA editor. Design and evaluation of computer/human interfaces: issues for librarians and information scientists. 25th Clinic on Library Applications of Data Processing (1988). Urbana, IL: University of Illinois, Urbana-Champaign, 1991.

[7] Woodsmall Rose Marie. Personal communication. Sept. 29, 2020.

[8] Contaxis N. Grateful Med: personal computing and user-friendly design. Circulating Now. National Library of Medicine, April 29, 2016. [cited 15 May 2021] Available From https://circulatingnow.nlm.nih.gov/2016/04/28/grateful-med-personal-computing-and-user-friendlydesign/

[9] Preuss DR, Sequeira EP, Graeff AS. Grateful Med on an institutional local area network. Proc Annu Symp Appl Med Care. 1992;488-90.

[10] Kingsland LC 3rd, Harbourt AM, Syed EJ, Schuyler PL. Coach: applying UMLS knowledge sources in an expert searcher environment. Bull Med Libr Assoc. 1993 Apr;81(2):178-83.

[11] National Library of Medicine (U.S.) Board of Regents. Improving health professionals' access to information: challenges and opportunities of the National Library of Medicine, a report of the Outreach Planning Panel of the Regents of the National Library of Medicine. Bethesda, MD: U.S. Department of Health and Human Services, National Institutes of Health, 1989.

[12] Lindberg DA. The National Library of Medicine and its role. Bull Med Libr Assoc. 1993 Jan; 81(1): 7173.

[13] Dorsch JL, Pifalo V. Rural health professionals and information access: a follow-up study. In: Lacroix EM, ed. Health information for the global village. Washington, DC: Local Organizing Committee, 7th International Congress on Medical Librarianship, 1995:6-10.

[14] Dorsch JL. Equalizing rural health professionals' information access: lessons from a follow-up outreach project. Bull Med Libr Assoc. 1997 Jan;85(1):39-47. 
[15] Wallingford KT, Ruffin AB, Ginter KA, Spann ML, Johnson FE, Dutcher GA. Outreach activities of the National Library of Medicine: a five-year review. Bull of the Med Libr Assoc. 1996 Apr;84(Supp 1):160.

[16] A proposal for more informative abstracts of clinical articles. Ad Hoc Working Group for Critical Appraisal of the Medical Literature. Ann Intern Med. 1987 Apr;106(4):598-604

[17] Ripple AM, Mork JG, Knecht LS, Humphreys BL. A retrospective cohort study of structured abstracts in MEDLINE, 1992-2006. J Med Libr Assoc. 2011 Apr;99(2):160-3. DOI: 10.3163/1536-5050.99.2.009.

[18] Ripple AM. Personal communication. April 26, 2021.

[19] Hubbard SM, Martin NB, Blankenbaker LW, Esterhay RJ Jr, Masys DR, Tingley DE, Stram MC, DeVita VT Jr. The Physician Data Query (PDQ) cancer information system. J Cancer Educ. 1986;1(2):79-87. DOI: $10.1080 / 08858198609527818$. 